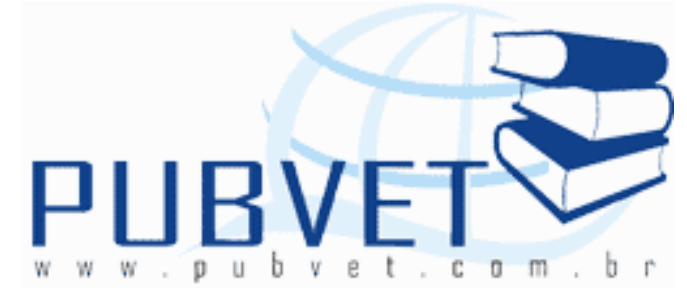

PUBVET, Publicações em Medicina Veterinária e Zootecnia.

\title{
Avaliação econômica da terminação de cordeiros em pastagem
}

José Carlos da Silveira Osório ${ }^{1,2,4}$; Sérgio Muñoz ${ }^{3}$; Maria Teresa Moreira Osório ${ }^{2,4}$; Roger Marlon Gomes Esteves ${ }^{2,4}$; Carlos Eduardo da Silva Pedroso ${ }^{4}$; Otoniel Geter Lauz Ferreira ${ }^{4}$

1 Professor Visitante Nacional Sênior da Universidade Federal da Grande Dourados/CAPES, ${ }^{2}$ Bolsista do CNPq. ${ }^{3}$ Médico Veterinário, Técnico da ARCO. ${ }^{4}$ Universidade Federal de Pelotas.

\section{Resumo}

O presente estudo teve por objetivo avaliar a viabilidade econômica da terminação de cordeiros em pastagem cultivada de Lotus subbflorus cv. El Rincón e Azevém anual (Lolium multiflorum Lam.) em 10 hectares, na Fazenda Sant 'Ana, município de Herval, RS. Para tanto foram avaliados os custos da pastagem e da comercialização; ganhos de peso corporal e características produtivas de 225 cordeiros, separados em dez lotes. O primeiro lote de animais entrou na pastagem em 02/07/2003 e o último saiu em 23/11/2003, em um período total de 145 dias, com lotação média de 71,7 cordeiros. Em média os cordeiros entraram na pastagem com peso corporal de 24,110 kg e saíram com peso corporal de 33,120 kg em um período de 48,2 dias para atingirem a condição de abate. Constatou-se variação importante nos ganhos de peso corporal dos cordeiros, entre e dentro de raças. Em 145 dias de utilização da pastagem foram produzidos $2.042,74 \mathrm{~kg}$ de cordeiro. $O$ custo 
OSÓRIO, J.C.S. et al. Avaliação econômica da terminação de cordeiros em pastagem. PUBVET, Londrina, V. 6, N. 19, Ed. 206, Art. 1377, 2012.

total da pastagem foi de $\mathrm{R} \$ 4.065,00$ e o retorno bruto pela venda dos cordeiros de $\mathrm{R} \$ 6.741,36$. Deste modo, obteve-se a rentabilidade de $65,84 \%$ do valor investido e lucro de $\mathrm{R} \$ 2.676,36$. Neste sentido a terminação de cordeiros para produção de carne, em pastagem cultivada foi viável economicamente.

Palavras-chave: Ovinos, alimentação, custos.

\section{Economic evaluation of the termination of lambs in pasture}

\section{Abstract}

The present study it had for objective to evaluate the economic viability of the termination of lambs in pasture cultivated of Lotus subbflorus cv. El Rincón and annual Azevém (Lolium multiflorum Lam.) in 10 hectares, the Sant'Ana Farm, city of Herval, RS. For the costs of the pasture and the commercialization had been in such a way evaluated; gain of body weight and productive characteristics of 225 lambs, separate in ten lots. The first lot of animals entered in the pasture in 02/07/2003 and the last one left in 23/11/2003, in a total period of 145 days, with average capacity of 71,7 lambs. On average the lambs had entered in the pasture with body weight of $24,110 \mathrm{~kg}$ and had left with 33,120 body weight of $\mathrm{kg}$ in a period of 48,2 days to reach the condition of abate. Important variation in the gain body weight of the lambs was evidenced, enters inside and of races. In 145 days of use of the pasture 2,042 had been produced, $74 \mathrm{~kg}$ of lamb. The total cost of the pasture was of $R \$ 4.065,00$ and the rude return for and the gain of the lambs of $R \$ 6.741,36$. In this way, it was gotten yield of $65,84 \%$ of the invested value and gain of $\mathrm{R} \$ 2.676$, 36. In this direction the termination of lambs for meat production, in cultivated pasture was viable economically.

Keywords: Sheep, feeding, costs. 
OSÓRIO, J.C.S. et al. Avaliação econômica da terminação de cordeiros em pastagem.

PUBVET, Londrina, V. 6, N. 19, Ed. 206, Art. 1377, 2012.

\section{INTRODUÇÃO}

A terminação de cordeiros para produção de carne de qualidade pode, através da utilização de pastagem, apresentar vantagens econômicas para o desenvolvimento da ovinocultura.

Dentro dessa orientação, apresenta-se como alternativa o engorde de cordeiros com base forrageira leguminosas em consórcio com gramíneas (Devendra \& Mcleroy, 1982; Sobrinho, 2001; Gonzaga, 2003) para incrementar quantitativa e qualitativamente a disponibilidade alimentar e suprir as necessidades do cordeiro; permitindo a plena manifestação de sua potencialidade produtiva.

Resultados obtidos por Ávila \& Osório (1996), Osório et al. (1999), Sá et al. (2008) e Costa et al. (2009ab), são exemplos do aumento da produção de carne de cordeiros em pastagens cultivadas. Figueiró (1975) verificou que os cordeiros criados em pastagem cultivada de estação fria tiveram peso de 27,13 $\mathrm{kg}$ aos 120 dias de idade, enquanto os criados em pastagem nativa apresentaram aos 120 dias de idade $15,63 \mathrm{~kg}$ no mesmo período. Ávila \& Osório (1996) da mesma forma, observaram maior desempenho de cordeiros em pastagem cultivada $(0,252 \mathrm{~kg} / \mathrm{dia})$ comparado aqueles produzidos em campo nativo $(0,179 \mathrm{~kg} / \mathrm{dia})$, todavia Osório et al. $(1998 \mathrm{~b}, 1999)$ também salientam significativa diferença na qualidade da carcaça dos cordeiros.

Os resultados deste último estudo salientados em Osório et al. (2002), mostram que os cordeiros das raças Ideal e Corriedale alimentados com pastagem cultivada apresentam, 5,64\% e 5,98\%, respectivamente, a mais de carcaça do que os alimentados em campo nativo. Além disso, os cordeiros em pastagem cultivada possuem 5,62\% (Ideal) e 5,66\% (Corriedale) a mais de pelego do que os de campo nativo. Considerando que a carcaça e o pelego têm maior valorização que os demais componentes corporais, a comercialização baseada apenas no peso corporal estaria prejudicando duplamente o produtor que utiliza a pastagem cultivada na alimentação dos cordeiros.

Essa proporção maior de carcaça e pelego para os cordeiros alimentados com pastagem cultivada, em relação aos com campo nativo está compensada, 
OSÓRIO, J.C.S. et al. Avaliação econômica da terminação de cordeiros em pastagem. PUBVET, Londrina, V. 6, N. 19, Ed. 206, Art. 1377, 2012.

na composição do peso corporal dos cordeiros alimentados com campo nativo, nas vísceras verdes; ou seja, os cordeiros em campo nativo das raças Ideal e Corriedale apresentaram, respectivamente, $11,59 \%$ e $11,15 \%$ a mais de vísceras verdes do que os criados em pastagem cultivada.

Entretanto, esses experimentos, como muitos outros, carecem de análise econômica, para ajudar na quantificação da valorização da qualidade e na decisão de investimentos com previsões de retorno financeiro.

O presente estudo objetiva contribuir, avaliando aspectos econômicos e práticas viáveis na terminação de cordeiros em pastagem cultivada.

\section{MATERIAL E MÉTODOS}

O experimento foi conduzido na propriedade rural denominada Fazenda Sant' Ana, situada no município de Herval, RS.

Foram utilizados 225 cordeiros, separados em dez lotes, segundo raça e data de entrada na pastagem. O critério para retirada dos cordeiros da pastagem e envio para abate, foi a condição corporal, seguindo a metodologia descrita por Osório \& Osório (2003), na qual, por avaliação individual e tátil do cordeiro é atribuído um índice de 1 (excessivamente magro) a 5 (excessivamente gordo), com intervalos de 0,5 em 0,5. O mercado consumidor exigia uma condição corporal entre 2,5 e 3,5; permitindo percentual não superior a $16 \%$ de condiçãocorporal 2.

A pastagem cultivada utilizada para terminação dos cordeiros era constituída de Lótus El Rincón (Lotus subbflorus cv. El Rincón) e Azevém anual (Lolium multiflorum Lam.) tetraploide (Tama) em uma área de 10 hectares.

Para a dessecação foi utilizado glifosate na dose de dois litros por hectare, na segunda quinzena de março. A semeadura, em cobertura, foi realizada 30 dias após a dessecação (12 de abril). A adubação foi feita em maio, aproximadamente 30 dias após a semeadura, à lanço, utilizando-se 160 kg por hectare, além de uma aplicação em cobertura de uréia em junho, na quantidade de $50 \mathrm{~kg}$ por ha $(22,5 \mathrm{~kg} \mathrm{~N})$. 
OSÓRIO, J.C.S. et al. Avaliação econômica da terminação de cordeiros em pastagem. PUBVET, Londrina, V. 6, N. 19, Ed. 206, Art. 1377, 2012.

A densidade de semeadura utilizada foi de $5 \mathrm{~kg}$ de Lotus El Rincón e 22 $\mathrm{kg}$ de Azevém anual por hectare.

A utilização da pastagem foi iniciada no dia 2 de julho, aproximadamente 75 dias após a semeadura (Tabela 1 ). O período de utilização da consorciação foi de 145 dias, de 02/07/2003 à 23/11/2003, com um número total de 225 cordeiros.

Em diversos momentos mais de um lote esteve presente na pastagem por algum intervalo de tempo. Deste modo, no mês de julho, nos sete primeiros dias havia oito cordeiros, a seguir, 14 dias com 51 cordeiros, quatro dias com 81 e quatro com 66, ou seja, uma média de 45,3 cordeiros por dia sobre a pastagem.

No mês de agosto, nos 11 primeiros dias, havia 83 cordeiros, a seguir, dez dias com 106, um com 100, três com 64, dois com 34 e quatro dias com 82 cordeiros, em média foram 85,8 cordeiros por dia sobre a pastagem.

No mês de setembro, nos cinco primeiros dias havia 82 cordeiros, a seguir, 11 dias com 59 cordeiros, oito com 80, quatro com 69 e dois dias com 49 cordeiros; em média foram 69,1 cordeiros por dia sobre a pastagem.

No mês de outubro permaneceram 90 cordeiros por dia sobre a pastagem.

No mês de novembro, nos três primeiros dias, havia 90 cordeiros e, posteriormente, durante 15 dias havia 69 cordeiros e, a seguir, cinco dias com 41 cordeiros; em média 65,7 cordeiros por dia sobre a pastagem.

Durante o período de 02 de julho até 23 de novembro, 145 dias, a média foi de 71,7 cordeiros por dia sobre a pastagem.

O custo da pastagem por hectare foi de $R \$ 406,50$, assim descriminados: $5 \mathrm{~kg}$ de Lotus El Rincón $=\mathrm{R} \$ 48,80,22 \mathrm{~kg}$ de azevem $=\mathrm{R} \$ 72,00,160 \mathrm{~kg}$ de adubo $=R \$ 157,10,50 \mathrm{~kg}$ de uréia $=R \$ 40,00,2$ litros de dessecante $=$ $\mathrm{R} \$ 26,40$ e em despesas diversas o gasto foi de $\mathrm{R} \$ 61,60$. Em termos percentuais, os referidos custos foram: 29,8\% com Rincon e Azevem, 48,5\% com adubo e uréia, 6,5\% com dessecante e 15,1\% nas demais despesas (mão de obra, trator, óleo, ....). 
OSÓRIO, J.C.S. et al. Avaliação econômica da terminação de cordeiros em pastagem. PUBVET, Londrina, V. 6, N. 19, Ed. 206, Art. 1377, 2012.

Foram utilizados dez lotes de cordeiros na pastagem, tomando-se a data de entrada e saída, peso corporal inicial e final, total de dias na pastagem, ganho de peso corporal diário dos lotes.

Os cordeiros foram comercializados pelo preço de mercado, distribuidoras Santa Fé (Pelotas) e Timmer (Porto Alegre), através do Conselho Regulador do Cordeiro Herval Premium.

Após o abate dos cordeiros, no frigorífico, foi determinado o estado de engorduramento da carcaça, visualmente, atribuindo-se um índice de 1 (excessivamente magra) a 5 (excessivamente gorda), com escala de 0,5, conforme descrito por Osório et al. (1998a) e Osório \& Osório (2003). O mercado consumidor exigia índices de estado de engorduramento da carcaça entre 2,5 e 3,5; permitindo percentual não superior a $16 \%$ de 2 .

A partir do valor pago pelos cordeiros, custos diversos (mão de obra, trator, óleo, ...) com os mesmos, foi calculado o custo total dos animais por lote. Foi calculado o valor de venda por animal, de cada lote, considerando o preço obtido pela carne e pela lã. Por diferença (valor de venda menos custo total) obteve-se o ganho obtido por animal para cada lote; igualmente, foi calculada a rentabilidade de cada lote no período de tempo (ganho em $\mathrm{R} \$$ dividido pelo custo total vezes 100 ).

\section{RESULTADOS E DISCUSSÃO}

$\mathrm{Na}$ avaliação das carcaças, no frigorífico, duas receberam índice 2,00 (magra), quarenta receberam índice 2,5 (ligeiramente magra), 152 carcaças receberam índice 3,0 (normal) e 31 carcaças receberam índice 3,5 (ligeiramente engordurada); portanto, $81,2 \%$ das carcaças foram avaliadas dentro do estado de engorduramente considerado normal e ligeiramente engorduradas, padrão na Denominação Específica de Carne Ovina de Qualidade do Cordeiro Herval Premium. Isso permite afirmar que os lotes de cordeiros estavam terminados e, correta a avaliação da condição corporal realizada pelo técnico de campo, onde o padrão buscado é entre 2,5 e 3,5. 
OSÓRIO, J.C.S. et al. Avaliação econômica da terminação de cordeiros em pastagem. PUBVET, Londrina, V. 6, N. 19, Ed. 206, Art. 1377, 2012.

Foram registrados os seguintes valores médios para os 225 cordeiros: peso corporal inicial de 24,110 kg, peso corporal final de 33,120 kg, ganho de peso corporal por cabeça de 9,010 kg, a pastagem foi utilizada por 48,2 dias, 0 ganho médio diário de peso corporal foi de $0,187 \mathrm{~kg}$, a média geral das carcaças foi de $13,920 \mathrm{~kg}$ e o rendimento na primeira balança (peso corporal no frigorífico em relação ao peso de carcaça fria) foi de $42,02 \%$.

Verifica-se, tabela 1, que a evolução de peso corporal diminuiu nos lotes que entraram mais tarde na pastagem e, isso, deve-se, especialmente, a diminuição da relação folha/colmo do azevém anual e, por consequência, do valor nutricional da pastagem e, ainda, da idade mais avançada dos cordeiros. Visto que, com a proximidade da maturidade ocorre diminuição da conversão alimentar e de ganho de peso em cordeiros em crescimento (Osório et al., 2002).

Tabela 1. Evolução durante o período de terminação

\begin{tabular}{|c|c|c|c|c|c|c|c|c|}
\hline Lote & Raça & $\begin{array}{c}\mathrm{N}^{\circ} \\
\text { Cor- } \\
\text { deiros }\end{array}$ & $\begin{array}{c}\text { Data } \\
\text { Entrada }\end{array}$ & $\begin{array}{c}\text { Data } \\
\text { Saída }\end{array}$ & $\begin{array}{c}\text { Peso } \\
\text { Inicial } \\
(\mathrm{Kg})\end{array}$ & $\begin{array}{c}\text { Peso } \\
\text { Final } \\
(\mathrm{Kg})\end{array}$ & $\begin{array}{c}\text { Dias na } \\
\text { Pasta- } \\
\text { gem }\end{array}$ & $\begin{array}{c}\text { Ganho } \\
\text { Diário } \\
(\mathrm{gr} .)\end{array}$ \\
\hline 1 & Texel-Ideal & 15 & $02 / 07$ & $26 / 07$ & 26,40 & 32,00 & 24 & 0,233 \\
\hline 2 & Texel-Ideal & 6 & $09 / 07$ & $21 / 08$ & 21,30 & 31,60 & 43 & 0,239 \\
\hline 3 & Várias Cruzas & 30 & $09 / 07$ & $25 / 08$ & 22,46 & 33,88 & 47 & 0,242 \\
\hline 4 & Ideal & 30 & $23 / 07$ & $22 / 08$ & 26,55 & 32,73 & 30 & 0,206 \\
\hline 5 & Várias Cruzas & 11 & $31 / 07$ & $24 / 09$ & 21,45 & 33,20 & 55 & 0,213 \\
\hline 6 & $\begin{array}{c}\text { Texel- } \\
\text { Corriedale }\end{array}$ & 23 & $12 / 08$ & $05 / 09$ & 31,80 & 37,17 & 24 & 0,223 \\
\hline 7 & $\begin{array}{c}\text { Ideal- } \\
\text { Corriedale }\end{array}$ & 28 & $27 / 08$ & $18 / 11$ & 18,80 & 34,28 & 84 & 0,184 \\
\hline 8 & Ideal & 20 & $27 / 08$ & $28 / 09$ & 24,90 & 32,48 & 31 & 0,246 \\
\hline 9 & Ideal- & 21 & $17 / 09$ & $03 / 11$ & 20,50 & 30,31 & 77 & 0,127 \\
\hline 10 & Corriedale & & & & & & & \\
\hline
\end{tabular}


OSÓRIO, J.C.S. et al. Avaliação econômica da terminação de cordeiros em pastagem. PUBVET, Londrina, V. 6, N. 19, Ed. 206, Art. 1377, 2012.

A raça Ideal apresentou ótimo potencia para produção de carne, observa-se que no lote de 20 cordeiros, foi obtido, em 31 dias na pastagem, ganhos de peso diário de 0,246 gramas.

Constata-se, pela análise financeira por lote, tabela 2, que a terminação de cordeiros em pastagem é bom investimento. A menor rentabilidade foi de 10,9\%, em 24 dias, para cordeiros procedentes do cruzamento de Texel $x$ Corriedale; mas, em 24 dias, também foi obtido uma rentabilidade de 39,92\% para cruzas de Texel $x$ Ideal.

As rentabilidades obtidas $(47,4 \%$ em 30 dias, $52,4 \%$ em 31 dias e $54,9 \%$ em 53 dias) na terminação de cordeiros da raça Ideal é economicamente viáveis.

Tabela 2. Dados financeiros por lote

\begin{tabular}{|c|c|c|c|c|c|c|c|c|}
\hline Lote & $\begin{array}{c}\text { No Cor- }^{\circ} \text { deiros } \\
\text { Valor } \\
\text { Pago } \\
(\mathrm{R} \$)\end{array}$ & $\begin{array}{c}\text { Custos } \\
\text { Diversos } \\
(\mathrm{R} \$)\end{array}$ & $\begin{array}{c}\text { Custo } \\
\text { Total } \\
(\mathrm{R} \$)\end{array}$ & $\begin{array}{c}\text { Valor } \\
\text { Venda } \\
(\mathrm{R} \$)^{1}\end{array}$ & $\begin{array}{c}\text { Ganho } \\
(\mathrm{R} \$)\end{array}$ & $\begin{array}{c}\text { Rentabi- } \\
\text { lidade }\end{array}$ & $\begin{array}{c}\text { Dias na } \\
\text { proprie- } \\
\text { dade }\end{array}$ \\
\hline 1 & $15^{*}$ & 52,80 & 0,50 & 53,30 & 74,58 & 21,28 & $39,92 \%$ & 24 \\
\hline 2 & $6 *$ & 42,60 & 0,50 & 43,10 & 75,69 & 32,60 & $75,64 \%$ & 43 \\
\hline 3 & $30 * *$ & 45,00 & 3,60 & 48,60 & 91,90 & 43,30 & $89,10 \%$ & 86 \\
\hline 4 & $30 * * *$ & 61,00 & 1,10 & 62,10 & 91,54 & 29,44 & $47,41 \%$ & 30 \\
\hline 5 & $11 * *$ & 55,00 & 0,50 & 55,50 & 88,80 & 33,30 & $60,00 \%$ & 55 \\
\hline 6 & $23 * *$ & 78,00 & 4,60 & 82,60 & 91,60 & 9,00 & $10,90 \%$ & 24 \\
\hline 7 & $28 * * * *$ & 50,00 & 3,40 & 53,40 & 86,29 & 32,89 & $61,59 \%$ & 84 \\
\hline 8 & $20 * * *$ & 57,30 & 0,60 & 57,90 & 88,27 & 30,37 & $52,45 \%$ & 31 \\
\hline 9 & $21 * * * *$ & 50,00 & 3,40 & 53,40 & 84,47 & 31,07 & $58,18 \%$ & 77 \\
\hline 10 & $41 * * *$ & 56,60 & 0,60 & 57,30 & 88,77 & 31,47 & $54,92 \%$ & 53 \\
\hline
\end{tabular}

${ }^{1}$ Carne + Lã. * não esquilados. ** $2 \mathrm{~kg}$ lãs cruzas à $\mathrm{R} \$ 4,50$ por kg. *** 1,9 $\mathrm{kg}$ lã Ideal à $\mathrm{R} \$ 8,00$ por kg. $* * * * 1,6 \mathrm{~kg}$ lã Ideal $\times$ Corriedale à $\mathrm{R} \$ 6,00$ por kg.

Vasconcelos et al. (2002) demonstra que em pastagens perenes de estação quente - gramão e tanzânia - é possível a utilização de maiores taxas 
OSÓRIO, J.C.S. et al. Avaliação econômica da terminação de cordeiros em pastagem. PUBVET, Londrina, V. 6, N. 19, Ed. 206, Art. 1377, 2012.

de lotação de 40 e 60 animais/ha, e obtiveram lucros anuais de, $R \$ 94,79 /$ ha e $R \$ 233,23 /$ ha para o gramão e $R \$ 198,79 /$ ha e $R \$ 891,95 /$ ha para a tanzânia para as duas lotações supracitadas, respectivamente. Isto demonstra que, por vezes, utilizar pastagens com maior capacidade de suporte pode resultar em maiores lucros por hectare. No entanto, os ganhos de peso por animal, normalmente, são próximos da metade, comparados aos obtidos com gramíneas de estação fria e leguminosas. Isto porque tais plantas de ciclo metabólico C3, têm muitas camadas de células do mesófilo (parede celular com maior degradabilidade no rúmen e conteúdo celular com maior proporção de proteinas, açúcares, minerais e lipidios). Fatos estes que demonstram que a lotação e a pastagem utilizada influem no lucro anual da terminação de cordeiros.

Igualmente, o sistema de produção influi no lucro e os resultados dependem dos insumos, fatores externos e inerentes aos sistemas utilizados e ao custo destes, que não são fixos no tempo e local. Nesse sentido, Macedo et al. (2000) encontraram uma renda líquida mais favorável para os cordeiros em confinamento em relação a pastagem de coastcross e, Santello et al. (2006) verificaram renda líquida superior na terminação em pastagem com suplementação em relação ao confinamento.

Dentro do sistema de confinamento, Siqueira et al. (2001) observaram que ovinos, fêmeas, abatidas com $28 \mathrm{~kg}$ de peso corporal proporcionaram maior renda líquida que as abatidas com $32 \mathrm{~kg}$ de peso corporal. 0 principal motivo da menor rentabilidade dos animais abatidos com $32 \mathrm{~kg}$ é a maior proximidade da maturidade, pois a medida que os animais se aproximam de tal fase fisiológica os ganhos de peso corporal diminuem.

Além dos aspectos ganhos de peso e rentabilidade, os cordeiros alimentados em pastagem cultivada de estação fria apresentam $6 \%$ a mais de rendimento de carcaça e $5 \%$ a mais de pele, do que os cordeiros em campo nativo; tanto na raça Ideal (Osório et al., 1999) como na raça Corriedale (Osório et al., 1998b). Esses resultados mostram que, os cordeiros em campo nativo apresentam $11 \%$ a mais de conteúdo gastro-intestinal do que os 
OSÓRIO, J.C.S. et al. Avaliação econômica da terminação de cordeiros em pastagem. PUBVET, Londrina, V. 6, N. 19, Ed. 206, Art. 1377, 2012.

cordeiros em pastagem cultivada, tanto na raça Corriedale como na Ideal. Portanto, em uma comercialização diferenciada e justa, os cordeiros em pastagem cultivada devem receber mais $11 \%$ (6\% no valor da carcaça e $5 \%$ no da pele) do que os em pastagem nativa. Isto, aumentaria a vantagem econômica à favor do uso de pastagem cultivada na terminação de cordeiros.

Os autores consideram importante avaliar a viabilidade econômica dos experimentos, quando pertinentes e, são conscientes que os mesmos devam ser atualizados periodicamente pelo produtor e/ou técnico, considerando as peculiaridades particulares de cada momento.

\section{CONCLUSÃO}

A terminação de cordeiros para produção de carne, em pastagem cultivada é uma alternativa para incrementar o potencial dos animais de maneira economicamente viável.

\section{REFERÊNCIAS BIBLIOGRÁFICAS}

Ávila, V.S.; Osório, J.C.S. Efeito do sistema de criação, época de nascimento e ano na velocidade de crescimento de cordeiros. Revista Brasileira de Zootecnia, Viçosa, v.25, n.5, p.1007-1016, 1996.

Costa, J.C.C.; Osório, J.C.S.; Osório, M.T.M.; Faria, H.V.; Mendonça, G.; Esteves, R.M.G. Produção de carne de ovinos Corriedale terminados em três sistemas de alimentação. Revista Brasileira de Agrociência, Pelotas, v.15, n.1-4, p.83-89, 2009a.

Costa, J.O.; Osório, J.C.S.; Osório, M.T.M.; Hashimoto, J.H.; Bonacina, M.; Esteves, R.M.; Mendonça, G. Crescimento e desenvolvimento dos componentes corporais de cordeiros Texel $\mathrm{x}$ Corriedale terminados em distintos sistemas. Pubvet, Londrina, v. 3, p. Ed. 104-Art. 703, 2009.

Devendra, C.; Mcleroy, G.B. Goat and sheep production in the tropics. London: Longman, 1982. $271 \mathrm{p}$.

Figueiró, P.R.P. Valerá a pena criar ovinos para abate? A Granja, Brasil, n.7, p.16-18, 1975.

Gonzaga, S.S. Em sistemas de produção intensivos. p.87-91. In: Sistema de Produção. Editado por N.M. de Oliveira. Bagé: Embrapa. 192p., 2003.

Macedo, F.A.F.M.; Siqueira, E.R.; Martins, N.E. Análise econômica da produção de carne de cordeiros sob dois sistemas de terminação: pastagem e confinamento. Ciência Rural, Santa Maria, v.30, n.4, p.677-680, 2000. 
Osório, J.C.; Osório, M.T.; Jardim, P.O.; Pimentel, M.; Pouey, J.; Lüder, W.; Cardellino, R.; Oliveira, N.; Borba, M.; Motta, L.; Esteves, R. Métodos para avaliação da produção de carne ovina: in vivo, na carcaça e na carne. Editora e Gráfica Universitária - UFPEL. Pelotas, RS. 1998a, 107p.

Osório, J.C.S; Sierra, I.; Oliveira, N.M.; Osório, MT.M.; Pimentel, M.A. Estudio comparativo de tres sistemas de producción de carne en ovinos Corriedale en Brasil. IN: Jornadas Científicas de la Sociedad Española de Ovinotecnia y Caprinotecnia, XXIIIa, Vitória-Gasteiz, España. p.465-468. 1998b.

Osório, J.C.S.; María, G.; Oliveira, N.M.; Osório, M.T.M.; Pouey, J.L.; Pimentel, M.A. Estudio de tres sistemas de producción de carne en corderos Polwarth. Revista Brasileira de Agrociência, Pelotas, v.5, n.2, p.124-130, 1999.

Osório, J.C.S.; Osório, M.T.M.; Oliveira, N.M.; Siewerdt, L. Qualidade, morfologia e avaliação de carcaças. Editora e Gráfica Universitária - UFPEL. Pelotas, RS. 2002. 196p.

Osório, J.C.S.; Osório, M.T.M. Produção de carne ovina: Técnicas de avaliação "in vivo" e na carcaça. Programa de Pós-graduação em Zootecnia, FAEM, UFPEL, Pelotas, RS. 2003, $73 p$.

Sá, C.O.; Sá, J.L.; Muniz, E.N.; Costa, C.X. Aspectos técnicos econômicos da terminação de cordeiros à pasto e em confinamento. Tecnologia \& Ciência Agropecuária, João Pessoa, PB, v.2, n.3, p.47-55, 2008.

Santello, G.A.; Macedo, F.A.F.; Mexia, A.A; Sakaguti, E.S.; Dias, F.J.; Pereira, M.F. Características de carcaças e análise de custos de sistemas de produção de cordeiros $1 / 2$ Dorset Santa Inês. Revista Brasileira de Zootecnia, Viçosa, v.35, n.4, p.1852-1859, 2006.

Siqueira, E.R; Simões, C.D.; Fernandes, S. Efeito do sexo e do peso ao abate sobre a produção de carne de cordeiro. I. Velocidade de crescimento, caracteres quantitativos da carcaça, $\mathrm{pH}$ da carne e resultado econômico. Revista Brasileira de Zootecnia, Viçosa, v.30, n.3, p.844-848, 2001.

Sobrinho, A.G.S. Produção de cordeiros em pastagem. In: Simpósio Mineiro de Ovinocultura, 10, Lavras, MG. p.63-97. 2001.

Vasconcelos, V.R.; Wander, A. E.; Sousa, F.B.; Barros, N.N.; Leite, E.R.; Neiva, J.N.M.; Pimentel, J.C.M. Viabilidade econômica da terminação de cordeiros em pastagem cultivada. In: Reunião Anual da Sociedade Brasileira de Zootecnia, 2002, Recife. p.1-3. 